\title{
Methods for assessing acid and metalliferous drainage mitigation and carbon sequestration in mine waste: a case study from Kevitsa mine, Finland
}

\author{
RJ Savage Cardiff University, and Geochemic Ltd, UK
}

S Pearce Mine Environment Management Ltd, UK

S Mueller Boliden Mines, Sweden

A Barnes Geochemic Ltd, UK

P Renforth Cardiff University, UK

D Sapsford Cardiff University, UK

\begin{abstract}
Previous studies suggest that the weathering of magnesium silicate minerals such as olivine, through the carbonation process, has the potential to sequestrate large amounts of $\mathrm{CO}_{2}$. In addition, as a result of alkalinity production, the beneficial impact of the process with respect to acid mine drainage (AMD) mitigation has been identified, although has been less well studied. The carbonation process is a potentially important aspect to assess as part of mine site waste characterisation and management. However, to date a standardised, practical and cost-effective methodology to assess the potential of carbonation to occur within mine waste facilities has yet to be developed and utilised widely.

Within this study we present a case study from the Finnish nickel mine, Boliden Kevitsa, for which we have assessed the potential for carbon sequestration and AMD mitigation within ultramafic waste rock and tailings storage facilities over life-of-mine (LOM) and closure timescales. As part of the work carried out a set of laboratory tests and analytical tools have been developed that are practical, cost-effective and short duration and have potential to form the basis for standardised testing methodology. It has been demonstrated as a result of the work carried out that the waste rock storage facilities may offer an important role with respect to carbonation processes, as well as the tailings storage facility. This finding is significant given that to date, tailings facilities have generally been considered as having the most potential for carbonation processes, and as such have been the focus of most research. This finding was made possible because of the consideration of physical and thermodynamic aspects such as gas flux and waste fragmentation as part of the assessment methodology as well as the pure geochemical rate-based process of carbonation, which typically is the focus of similar studies.
\end{abstract}

Keywords: mineral carbonation, magnesium carbonates, carbonation potential, carbonation rate, AMD

\section{$1 \quad$ Introduction}

\section{$1.1 \quad$ Study rational}

It is well understood that ultramafic mine waste has the potential to sequestrate significant amount of atmospheric $\mathrm{CO}_{2}$. Various published studies have shown the potential emissions offset that passive mineral carbonation may have on net mine operation emissions in locations where ore geology promotes carbonation (e.g. Li et al. 2018; Wilson et al. 2009; Renforth 2019). Within this study we have designed and implemented novel methodologies for assessing carbon capture potential (CCP) of waste rock and tailings, while also assessing the potential implications of such CCP on acid mine drainage (AMD) systems. 
The methods presented have the potential to be implemented at all stages of the mine cycle, from exploratory core material to closure planning.

The site presented in this study is the open pit Boliden Kevitsa Nickel operation, located in the Lapland region of Northern Finland. The Kevitsa nickel sulphide deposit (Ni-Cu-PGE) sits within an ultramafic cumulate, within the central Lapland greenstone belt (CLGB). Potential suitability for CCP assessment was identified due to nickel ore being hosted within a composite olivine-pyroxenite/websterite complex (Maier et al. 2015).

The abundance of magnesium silicate mineralogy at the Kevitsa site, as well as the availability of waste rock and tailings, make the site a primary candidate for assessing passive carbonation rates as well as the viability for enhanced carbonation schemes. The core research aim of this study was to characterise and quantify the potential suitability of the Kevitsa mine waste and tailings for large-scale carbon capture and storage.

\subsection{Mineral carbonation}

\subsubsection{The importance of mineral carbonation}

Review studies such as Li et al. (2018) and Leung et al. (2014) have shown that mines that produce by-products of suitable geochemical make up can be utilised as long-term carbon fixing locations. Carbon mineralisation is the process of transforming atmospheric $\mathrm{CO}_{2}$ into carbonate minerals through weathering of calcium, magnesium and iron oxide silicate minerals (Lackner 2003).

\subsubsection{Carbon mineralisation kinetics and equilibrium modelling}

The chemical process involved in the mineralisation of silicate minerals through aqueous carbonation consists of two main steps; dissolution of $\mathrm{Mg}$ or Ca bearing silicates and precipitation of carbonates such as magnesite and calcite (Prigiobbe et al. 2009). The basic carbonation reaction can be shown through the reactions of $\mathrm{MgO}$ and $\mathrm{CaO}$ with $\mathrm{CO}_{2}$, refer to Equations 1 and 2 (Herzog 2002), as well as the reaction between forsterite $\left(\mathrm{Mg}_{2} \mathrm{SiO}_{4}\right)$ and $\mathrm{CO}_{2}$, Equation 3.

$$
\begin{gathered}
\mathrm{CaO}+\mathrm{CO}_{2} \rightarrow \mathrm{CaCO}_{3} ; \Delta \mathrm{H}=179 \mathrm{~kJ} / \mathrm{mole} \\
\mathrm{MgO}+\mathrm{CO}_{2} \rightarrow \mathrm{MgCO}_{3} ; \Delta \mathrm{H}=118 \mathrm{~kJ} / \mathrm{mole} \\
\mathrm{Mg}_{2} \mathrm{SiO}_{4}+2 \mathrm{CO}_{2} \rightarrow 2 \mathrm{MgCO}_{3}+\mathrm{SiO}_{2}
\end{gathered}
$$

The understanding of stable carbonate phases within $\mathrm{CO}_{2}$ reservoirs is essential in understanding precipitation kinetics and as such CCP of a material. A lack of equilibrium thermodynamic data for mineral and fluid reactions exists within modelling data, such as those used in PHREEQC, a geochemical modelling program developed by the United States Geological Survey (USGS). Although a large amount of experimental determinations exist, variability in experimental data related to natural precipitates, particularly at near surface temperature and pressure mean uncertainties exist (Bickle et al. 2013). This is a significant issue when the interactions between $\mathrm{CO}_{2}$ and $\mathrm{H}_{2} \mathrm{O}$ fluids within host material are important in determining the amount of $\mathrm{CO}_{2}$ that can be trapped in solution or precipitated as a solid carbonate (Kaszuba et al. 2013).

\section{Methodology}

\subsection{Research design}

The study was designed to assess the suitability of the Kevitsa operation for large-scale carbon capture schemes through both mineralogical/elemental analysis and novel carbonation rate testing. Figure 1 shows the research design plan that was followed within this study. 


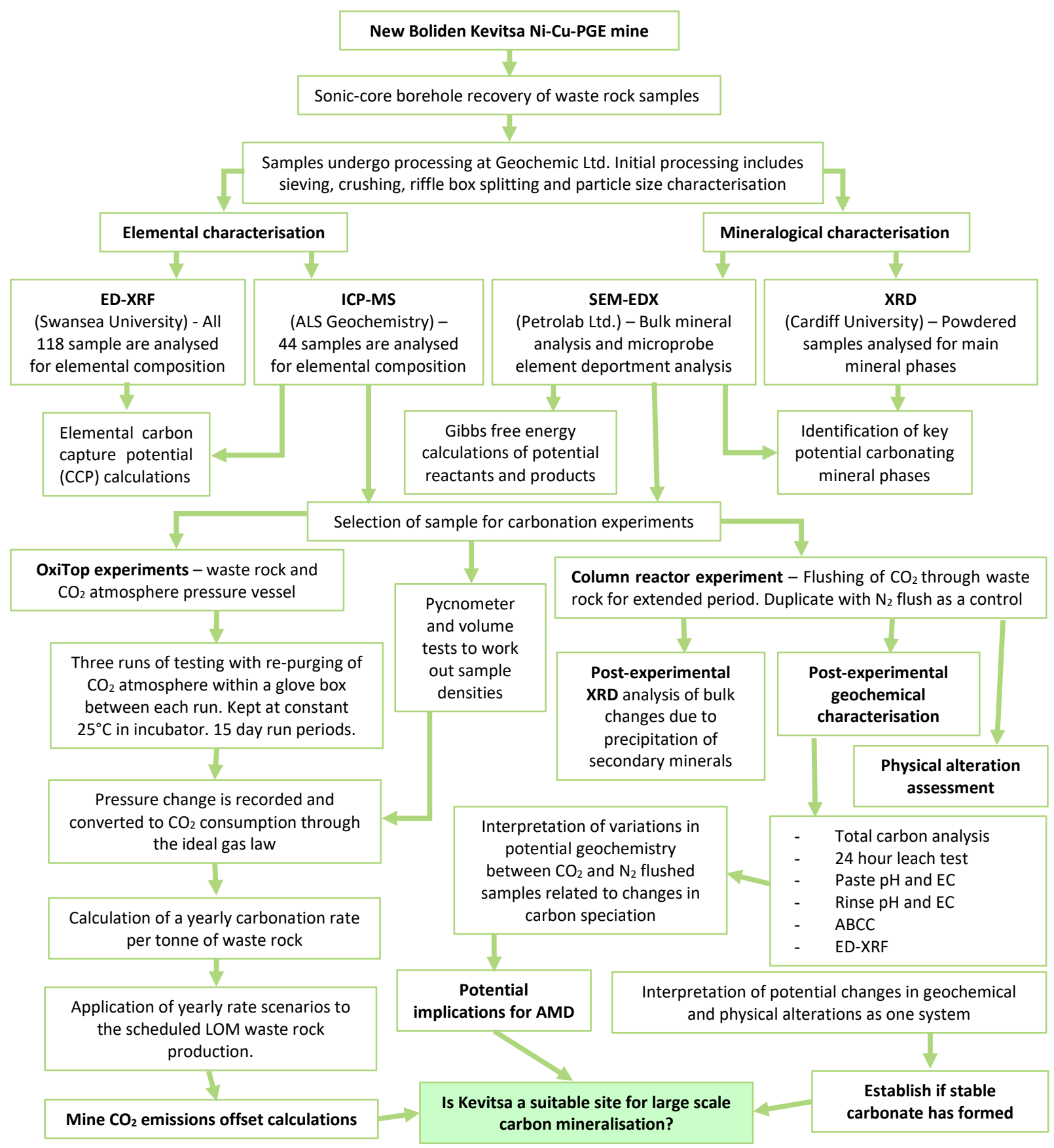

Figure 1 Research design flow diagram. ED-XRF - energy-dispersive X-ray fluorescence; ICP-MS inductively coupled plasma mass spectrometry; SEM-EDX - scanning electron microscope energy-dispersive X-ray spectroscopy; XRD - X-ray powder diffraction; CCP - carbon capture potential; LOM - life-of-mine; AMD - acid mine drainage; EC - electrical conductivity; ABCC acid buffering characterisation curve

\subsection{Sample preparation}

A total of 118 samples were collected via sonic drill coring and analysed for geochemical properties at Geochemic Ltd, with quality assurance/quality control (QA/QC) undertaken at ALS Laboratories, Ireland. Untreated waste rock and tailings samples were prepared and sorted through sieving ( $22 \mathrm{~mm}$ to $<2.3 \mathrm{~mm}$ ) as well as drying and crushing/pulverising of larger sample fractions.

The sieved fraction $<22 \mathrm{~mm}$ was used for elemental analysis. The samples were crushed and pulverised for powdered analysis. Pre-pulverising samples were split using a riffle box to homogenise them. Sample 
preparation included loading of $10 \mathrm{~g}$ of samples into sample pots, $35 \mathrm{~mm}$ Sci-Med standard, with $4 \mu \mathrm{m}$ polythene film laid across the sampling window. Samples were pressed, and sample thickness measured for input into the spectrometer user software.

\subsection{Sample characterisation}

\subsubsection{Elemental characterisation - inductively coupled plasma mass spectrometry (acid digestion)}

Forty-four samples, pre-selected by Geochemic Ltd, were sent for elemental analysis at ALS Geochemistry Ltd. The samples were analysed using inductively coupled plasma mass spectrometry (ICP-MS) after a four-acid digestion, the method is standardised at ALS with the method code ME-MS61L. The samples were analysed for a 48-element suite with acid digestion used to enhance detection limits through dissolution of minerals, reducing oxide formation to $<0.5 \%$.

\subsubsection{Elemental characterisation - energy-dispersive X-ray fluorescence}

All 118 waste rock samples were sent for elemental analysis using energy-dispersive X-ray fluorescence (ED-XRF) spectrometry. Analysis was carried out at Swansea University using a Rigaku NEX CG ED-XRF Spectrometer. The spectrometer analysed, non-destructively, for major and minor atomic elements between $\mathrm{Na}$ and $\mathrm{U}$. To reach a lower detection limit than conventional ED-XRF spectrometers the NEX CG used polarised excitement in coalition with close coupled cartesian geometry (CG) optical kernel. The spectrometer was powered by Rigaku's qualitative and quantitative software, RPF-SQX which allowed profile fitting with minimal standards.

\subsubsection{Mineralogical characterisation - scanning electron microscope energy-dispersive X-ray spectroscopy}

Quantitative automated mineralogical analysis was undertaken at Petrolab Ltd to characterise the bulk mineral composition of the Kevitsa waste rock material. Eleven waste rock and tailings samples of varying known geochemical make up were analysed.

Each of the samples were used to create a polished block which was carbon coated to $10 \mathrm{~nm}$. The polished blocks from each sample were analysed using a ZEISS EVO MA 25 scanning electron microscope (SEM) fitted with a Bruker xFlash 6|60 X-ray detector for energy-dispersive X-ray spectroscopy (EDX). A phase mineral classification scheme was utilised for the waste rock samples using ZEISS Mineralogic Mining software, which controlled both the SEM and the EDX instruments. Mineral phase mapping mode was employed using mineralogic mining software that acquired mineral data on a defined pixel spacing which considered mineral grain size and texture in coalition with the SEM magnification. Reporting of the sample mineralogy took the form of weight percentage of each mineral.

\subsubsection{Mineralogical characterisation - X-ray diffraction}

For quality assurance purposes the same 11 samples that were analysed for mineralogy using SEM-EDX were sent for X-ray diffraction (XRD) powder analysis of the mineral composition. Due to the differences in methods used in SEM-EDX and XRD mineralogy analysis the results of these tests are not directly comparable but provide clarification of the dominant mineral phases. Mineral phases that make up $<10 \%$ of the sample mass were not detectable using XRD analysis, therefore SEM-EDX and XRD are not directly comparable. The XRD analysis was carried out at Cardiff University using a Philips PW1710 Automated Powder Diffractometer, which used a copper (CuK $\alpha$ ) radiation power source at $35 \mathrm{kV} 40 \mathrm{~mA}$. The XRD was operated using PW1877 APD version 3.6 software while phase identification was carried out using PW1876 PC-identify version 1.0b software. 


\subsection{Carbon capture potential calculations}

The maximum CCP for the waste rock at Kevitsa was calculated using an adjusted version of the Steinour equation devised in Renforth (2019). The equation uses elemental oxide composition to estimate the maximum CCP. Equation 4 shows the CCP calculation used in this study.

$$
\left(\frac{1000}{100}\right) \cdot\left(\frac{\mathrm{CaO}}{M_{W(\mathrm{CaO})}}+\frac{\mathrm{MgO}}{M_{W(\mathrm{MgO})}}+\frac{\mathrm{Na}_{2} \mathrm{O}}{M_{W\left(\mathrm{Na}_{2} \mathrm{O}\right)}}+\frac{\mathrm{K}_{2} \mathrm{O}}{M_{W\left(\mathrm{~K}_{2} \mathrm{O}\right)}}-\frac{\mathrm{SO}_{4}}{M_{W\left(\mathrm{SO}_{4}\right)}}-\frac{P_{2} \mathrm{O}_{5}}{M_{W\left(P_{2} \mathrm{O}_{5}\right)}}\right) \cdot M_{W\left(\mathrm{CO}_{2}\right)}=C C P\left(\frac{\mathrm{kg}_{\mathrm{CO}_{2}}}{\text { tonne }_{(\text {Minewaste })}}\right)
$$

where:

$$
M_{W(\text { oxide })}=\text { molecular weight of the oxide }
$$

Equation 4 requires ICP-MS or ED-XRF analysis to identify maximum CCP based solely on elemental composition (expressed as oxides). The outputs represent the maximum potential of the material to mineralise carbon into carbonate and does not take into consideration variables that might affect carbonation and carbonation rates such as temperature, known reaction rates, pressure, moisture content and particle size distribution (PSD).

\subsection{OxiTop ${ }^{\circledR}$ carbon dioxide consumption tests}

To analyse the potential rate of mineral carbonation a novel method of using pressure reduction within a reactor vessel was utilised. Using WTW's OxiTop ${ }^{\circledR}$ sensors, pressure within a sealed vessel containing waste rock/tailings samples, see Figure 2(a), was logged over 15-day periods. The method was an adaptation of a standard method described in Platen and Wirtz (1999) for measurement of oxygen consumption. The ideal gas equation was used to calculate moles of carbon dioxide within a sealed vessel containing waste rock/tailings and $\mathrm{a} \mathrm{CO}_{2}$ atmosphere (99.995\%), one atmosphere, created by purging the vessels headspace and sample within a glove box sealed environment, see Figure 2(a). This method would simplify the standard method by replacing normal atmospheric gas make up with a pure $\mathrm{CO}_{2}$ atmosphere which would isolate the reactions to the carbonate system allowing calculation of reactions between the individual sample and carbon dioxide. A $10 \%$ moisture content, by dry weight, was employed within the samples used to replicate measured field conditions while the vessels, during their experimental runs were kept within a temperature at a constant $25^{\circ} \mathrm{C}$.

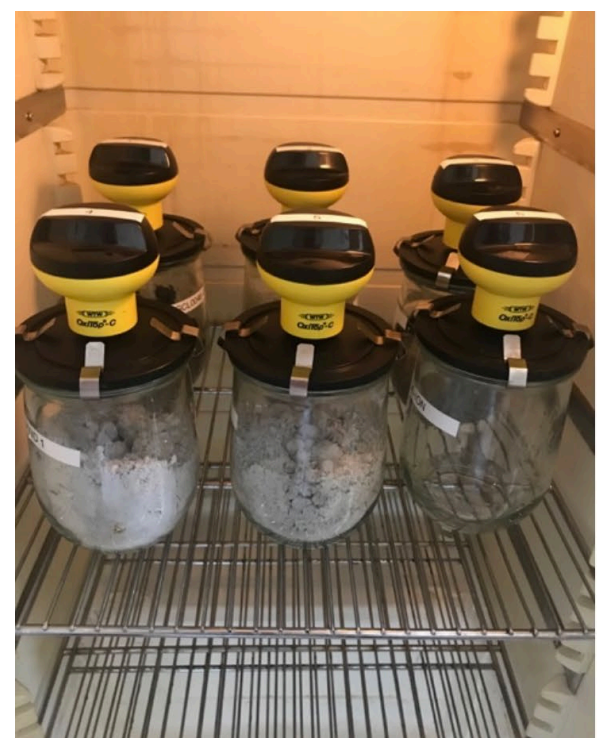

(a)

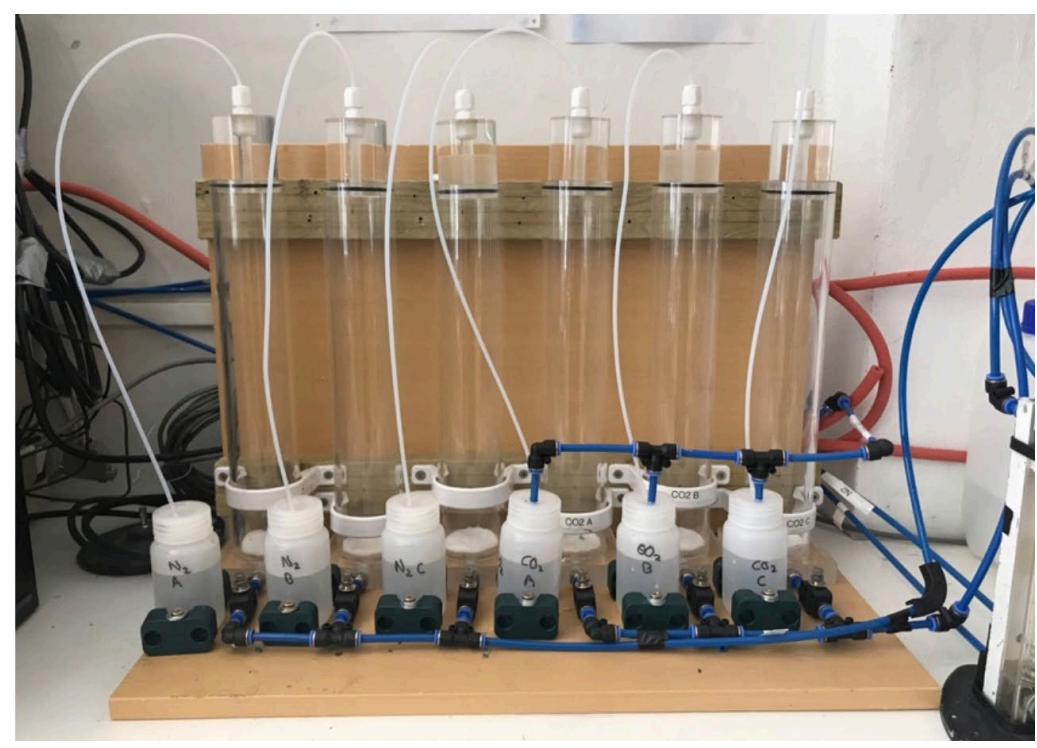

(b)

Figure 2 (a) OxiTop vessels; (b) reactor column test 
To allow quantification of the method repeatability, a triplicate of a sample was analysed in each run. Due to time constraints it was concluded that three cycles of experiments at 15 days each was feasible within the timescale of the project. Sample WR1 was chosen as the triplicate sample for analysis, due to the complete geochemical characteristic data available for the sample. To establish a differentiation between mineral carbonation, absorption onto surfaces and aqueous diffusion, sample WR1 was maintained in all three cycles with a re-purge of $\mathrm{CO}_{2}$ carried out between runs. This allowed correction of the carbonation rate to discount the initial potential drop in pressure due to physiochemical absorption onto surfaces and into solution.

\subsection{Carbon dioxide column reactor tests}

A bespoke reactor column experiment was designed to test geochemical changes in the Kevitsa waste rock in response to continuous flushing with $\mathrm{CO}_{2}$ over a seven-week timescale. This test allowed not only an assessment of the potential weathering of silicate minerals and precipitation of stable carbonates; it allowed a reassessment of the AMD properties of the waste rock once the material had been flushed within $\mathrm{CO}_{2}$ for an extended period.

\subsubsection{Reactor column test set-up}

Figure 2(b) shows the set-up of the reactor columns designed for this study. Within the set-up, six columns containing waste rock can be continuously flushed with gas over an extended period of time. To provide comparative data, three of the columns were flushed with nitrogen, while the other three were flushed with carbon dioxide. For comparability, the same waste rock was used within all six reactor columns (WR2) which was riffle box split to homogenise and reduce potential bias in results due to PSD variations. The particle size fraction used in this test was $<22 \mathrm{~mm}$ particles which were further crushed to $<6.3 \mathrm{~mm}$. The $\mathrm{CO}_{2} / \mathrm{N}_{2}$ flush within the columns was consistent throughout the seven-week period with the gases being humidified before insertion into the columns and an outlet bubbler system employed to measure the rate of gas flow. The moisture content within the samples were consistent throughout the set, $10 \%$, while the temperature was consistently between $21^{\circ} \mathrm{C}$ and $23^{\circ} \mathrm{C}$ during the experimental period.

\subsubsection{Post-experiment geochemical characterisation}

After the experimental period finished the sample columns were disconnected and dried at $60^{\circ} \mathrm{C}$ within an oven for 48 hours, with weight measurements taken before and after. Photos of the column material before and after removal from the columns were taken to consider any physical changes such as mineral alterations to the top of the sample and cementation of the material. The geochemical tests carried out on the column samples included total carbon analysis, 24-hour de-ionised water leach tests, paste and rinse $\mathrm{pH} / \mathrm{EC}$ (electrical conductivity), acid buffering characterisation curve (ABCC) and ED-XRF analysis.

\section{$3 \quad$ Results}

\subsection{Mineralogical characterisation results}

All 11 of the samples sent for mineralogy phase characterisation are dominated by amphibole group mineral tremolite and high-Ca clinopyroxene (diopside-augite). Olivine (forsterite), which is regarded as the main sequestration mineral within this study, is identified as having a minor presence in the samples presented with an average forsterite content of 6.35 wt. percent. Serpentine which is also regarded as a key mineral in the mineral carbonation process was identified in a trace capacity with an average content of $0.97 \%$ across the sample set. Table 1 shows the minimum, maximum and average contents of the dominating tremolite and high-Ca clinopyroxene mineral phases as well as olivine, serpentine and enstatite. 
Table 1 Minimum, maximum and mean values for selected mineral phases

\begin{tabular}{lccc}
\hline Mineral phase & Minimum (\%) & Maximum (\%) & Mean average (\%) \\
\hline Tremolite & 19.10 & 56.00 & 34.86 \\
$\begin{array}{l}\text { High-Ca Clinopyroxene } \\
\text { (Diopside-Augite) }\end{array}$ & 21.10 & 54.30 & 36.42 \\
Olivine (Forsterite) & 1.40 & 9.90 & 6.35 \\
Orthopyroxene (Enstatite) & 4.80 & 11.80 & 7.67 \\
Serpentine & 0.40 & 1.90 & 0.97 \\
\hline
\end{tabular}

\subsection{Elemental characterisation}

The elemental composition of 112 samples was analysed using ED-XRF analysis. This was performed for the purpose of validating the results of ICP-MS analysis of the reduced sample suite (43 samples). The main elements of interest were designated as $\mathrm{Mg}$ and $\mathrm{Ca}$ due to their relation to magnesium and calcium silicate minerals. Due to the known resolution benefits of ICP-MS for magnesium detection this methods' results have been used in calculations for CCP.

\subsubsection{Inductively coupled plasma mass spectrometry analysis key findings}

The mean $\mathrm{Mg}$ content was observed as $12.40 \%$ while the maximum and minimum values were calculated at $14.05 \%$ and $6.72 \%$, respectively. The mean content for Ca was $8.79 \%$ with a maximum content of $10.86 \%$ and a minimum value of $5.51 \%$.

\subsubsection{Carbon capture potential results}

ICP-MS data for the 43 tested samples was used to assess CCP. Overall the mean CCP was calculated at $319.37 \mathrm{~kg}\left(\mathrm{CO}_{2}\right)$ per $\mathrm{t}$ (waste rock) while the minimum value was $182.21 \mathrm{~kg}\left(\mathrm{CO}_{2}\right)$ per $\mathrm{t}$ (waste rock) and the maximum was $368.69 \mathrm{~kg}\left(\mathrm{CO}_{2}\right)$ per $\mathrm{t}$ (waste rock). Due to the known relation between magnesium silicates and carbon mineralisation a strong, positive, linear relationship was observed between magnesium content and CCP. An $\mathrm{R}^{2}$ trend value of 0.9361 was calculated between Mg content and CCP.

\subsection{Column reactor results}

\subsubsection{Physical observations}

Before the samples were removed from the reactor columns, any physical alterations to the surfaces of the samples were noted. It was observed that nitrogen purged columns (C1-C3) showed no obvious alteration to the surface morphology. Column 4, carbon dioxide purged, showed less obvious cementation at the surface layer although a white-grey crust was observed on some of the larger particle sizes. More obvious surface morphology changes were observed within columns 5 and 6 with clear cementation and white-grey crusting on the surface on the samples, see Figure 3. 


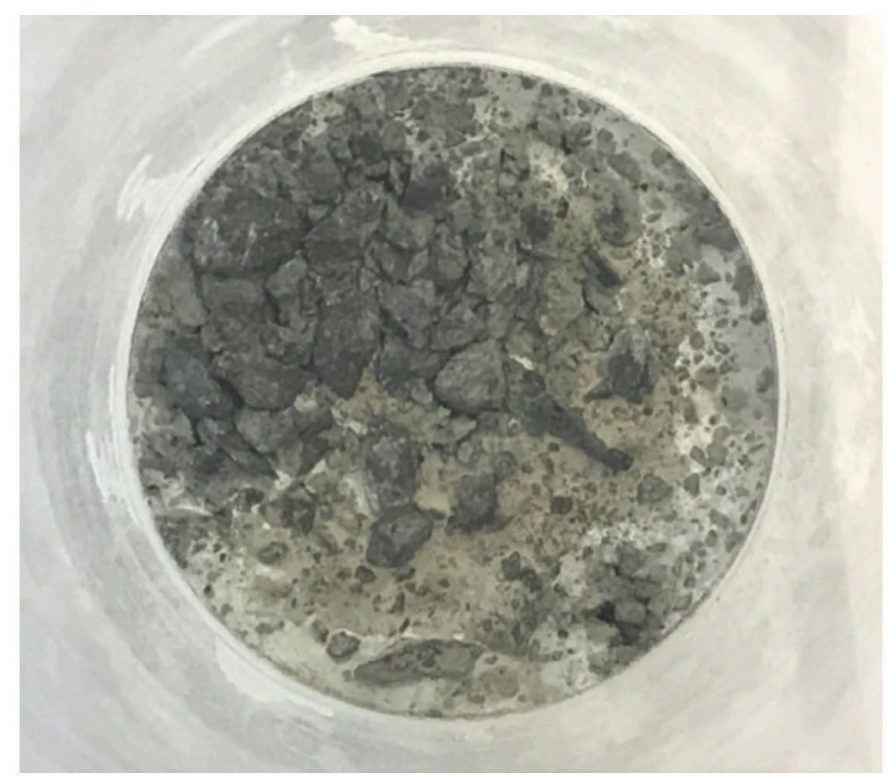

Figure 3 Post-experimental column 5 observation photos

\subsubsection{Reactor column 24 hour leach tests}

The waste rock material within the reaction columns were analysed for changes in water soluble constituents using a 24 hour deionised water leach test with a liquid solid ratio of 2:1. After the 24 hour mixing period the samples were filtered and analysed for dissolved total inorganic carbon (TIC), $\mathrm{pH}$ and EC. Figure 4 shows the results of these test for the six column reactors, the columns $\mathrm{C} 4-6$ had significantly higher TIC and pH values indicating that increased levels of dissolved carbonates were present in the leachate.
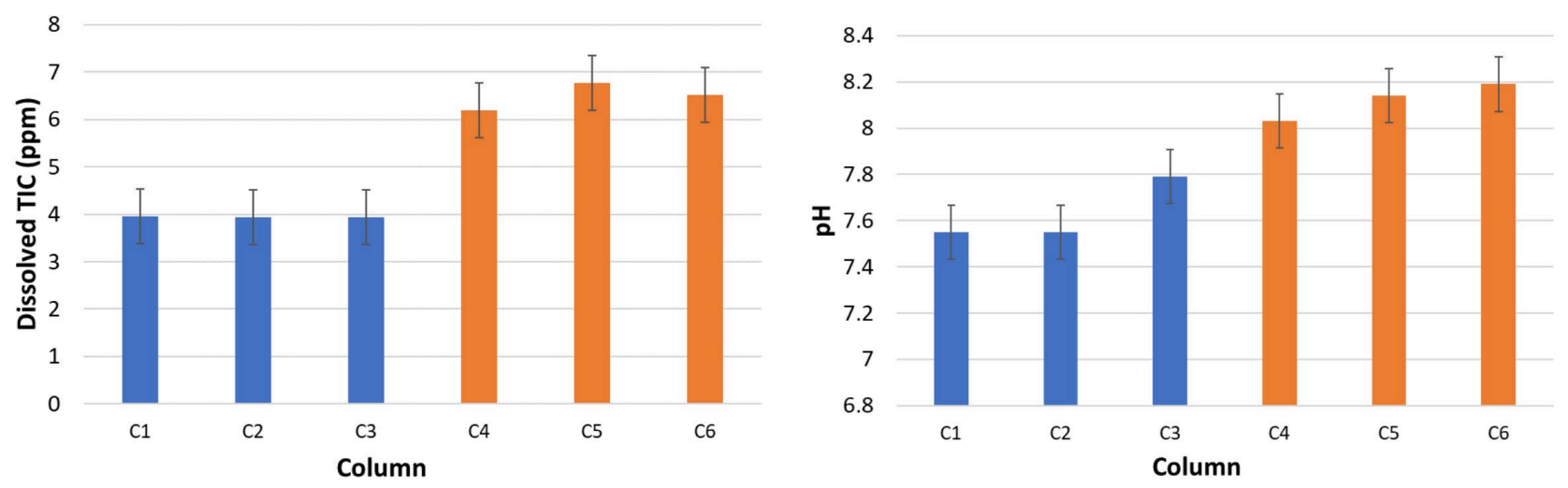

Figure 4 Twenty-four hour 2:1 leach test geochemistry results - dissolved total inorganic carbon and pH. C1-C3 were exposed to $\mathrm{N}_{2}$ while $\mathrm{C} 4-\mathrm{C} 6$ were exposed to $\mathrm{CO}_{2}$

Inductively coupled plasma optical emission spectrometry (ICP-OES) analysis was undertaken on the leachates of each of the columns. There was a clear differentiation between the $\mathrm{Mg}$ and Ca composition of the reactor column leachates. Magnesium compositions had a mean content of $51.80 \mathrm{mg} / \mathrm{L}$ within C4-C6 while C1-C3 held a mean value of just $20.25 \mathrm{mg} / \mathrm{L}$. Calcium content was lower within the carbon dioxide columns, although the difference factor was much lower than Mg. Mean Ca composition within C1-C3 was $44.12 \mathrm{mg} / \mathrm{L}$ while C4-C6 held a mean of $36.54 \mathrm{mg} / \mathrm{L}$. 


\subsection{OxiTop carbon dioxide vessel results}

The outputs for this experiment were in the form of pressure (hPa) which were then converted using the ideal gas law to measure reduction in carbon dioxide within each of the vessels $\left(\mathrm{CO}_{2}\right.$ consumption). Figure 5 shows the calculated carbonation rates of the samples analysed, using the ideal gas law to estimate reduction in $\mathrm{CO}_{2}$, which have been blank corrected using a water blank vessel run. Two main stages of carbon dioxide exchange within the vessels are clear: initial surface absorption and porewater dissolution and a more consistent mineral carbonation stage. Using the carbonation rates estimated within the test runs, calculations of yearly rates have been estimated for each sample. Two of the three runs for sample WR1 (runs 1 and 2) showed near identical mean rates of 1.29 and $1.30 \mathrm{~kg}\left(\mathrm{CO}_{2}\right)$ per $\mathrm{t}$ (waste rock) per annum while run 3 had lower estimated mean rate of $0.91 \mathrm{~kg}\left(\mathrm{CO}_{2}\right)$ per $\mathrm{t}$ (waste rock) per annum. The lower rate measured in run 3 was to be expected due to the previous two exposure periods to $\mathrm{CO}_{2}$. The higher olivine bearing samples WR2 and TA1 showed significantly higher estimated carbonation rates of $2.75 \mathrm{~kg}$ and $2.70 \mathrm{~kg}$ $\left(\mathrm{CO}_{2}\right)$ per $\mathrm{t}$ (waste rock) per annum, respectively.

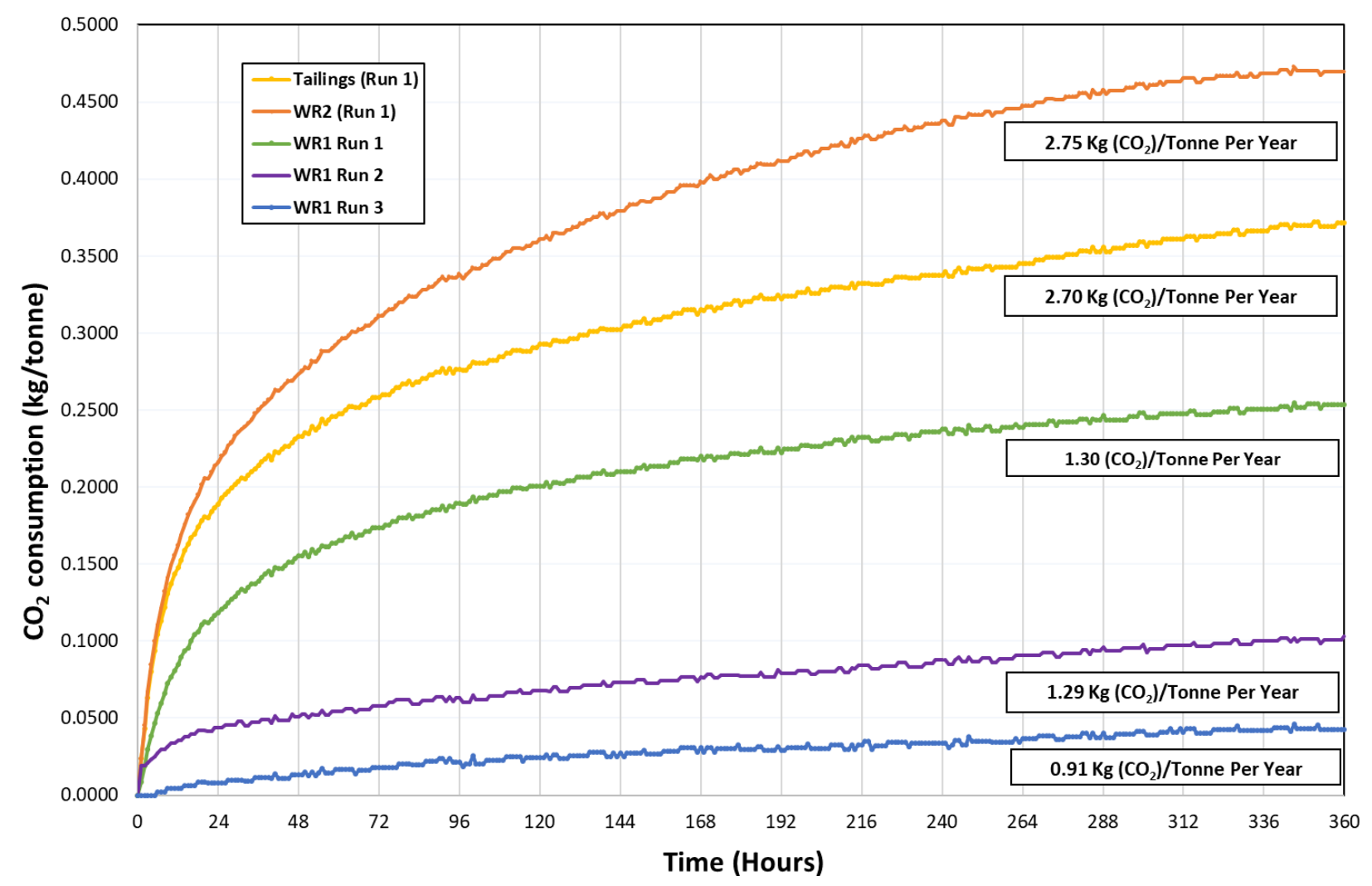

Figure 5 OxiTop calculated carbonation rates (run 1-3)

\section{$4 \quad$ Interpretations}

\subsection{Carbon capture potential results}

CCP calculated for the Kevitsa mine waste facility using the adjusted Steinour equation (Renforth 2019), reveals a mean value of $316 \mathrm{~kg}$ of $\mathrm{CO}_{2}$ per $\mathrm{t}$ of waste rock. If the mean CCP was to be applied to the entire usable fraction ( $<22 \mathrm{~mm}$ size) of the waste rock facility at $184 \mathrm{Mt}$ over the life-of-mine (LOM), Kevitsa would cumulatively consume $57.9 \mathrm{Mt}$ of $\mathrm{CO}_{2}$. It is noted that although this headline figure would offset estimated LOM CO 2 emissions over 50 times, although there are constraints to achieving the full hypothetical CCP, which may be constrained practically by kinetics. It remains unclear how a reaction facility can be designed and operated under the current business model of the mine. 


\subsection{Reactor column tests}

Studies such as Wilson et al. (2009) have demonstrated that carbonate minerals can form a crust on tailings in efflorescent form as well as been between particles as a carbonate cement. In all three of the carbon dioxide flushed columns cementing of the waste rock appeared to have occurred with an apparent matrix formation between particles. Similarly, within C5 and C6 clear crusting of the top of the waste material was observed suggesting potential precipitation of solid-state carbonates. Precipitation of carbonates between particles may cause limitations to carbonation due to reduced porosity and permeability. Such a reduction in these material properties may cause of reduction in reaction efficiency, stemming from reduced throughflow of $\mathrm{CO}_{2}$ and porewater (e.g. Kharaka et al. 2013; Stockmann et al. 2008).

The $\mathrm{pH}$ increase observed in the carbon dioxide flushed column leachates may be important to consider as the carbonation kinetics of olivine are faster in alkaline solutions (Kaszuba et al. 2013). The production of higher alkalinity within the carbon dioxide column leachates highlights the need for further study into the potential positive AMD implications, such as reduced acidity and metals release, that enhanced carbon mineralisation may have on geochemical aspects of mine closure planning. There is the potential that hydrated magnesium carbonates are more likely to have formed within the column reactor test, which are more likely at surface temperatures and pressures whereas kinetic limitations mean that precipitation of magnesite is less likely at temperature $<60^{\circ} \mathrm{C}$ (Königsberger et al. 1999).

\section{$4.3 \quad$ OxiTop vessels}

It was calculated that the highest linear carbonation rate, after initial pressure drop had be accounted for, was within sample WR2 at $2.75 \mathrm{~kg}\left(\mathrm{CO}_{2}\right)$ pert (waste rock) per annum. Sample WR1 which was run as a triplicate over three test runs showed a lower calculated carbonation rate across all three runs with mean rates of $1.30 \mathrm{~kg}$ per $\mathrm{t}$ (run 1), $1.29 \mathrm{~kg}$ per $\mathrm{t}$ (run 2) and $0.91 \mathrm{~kg}$ per $\mathrm{t}$ (run 3). The reduced rate observed within sample WR1 runs is likely related to a below waste rock average composition of forsterite $(1.4 \%)$ and enstatite (4.8\%), which are known for faster rates of dissolution compared to other $\mathrm{Mg}$-silicates (e.g. Oelkers 1999; Kaszuba et al. 2013). Following these experiments further tests are planned with varying $\mathrm{CO}_{2}$ partial pressures, $\mathrm{CO}_{2}$ concentrations, material particle sizes and testing temperatures.

\section{$5 \quad$ Implications of carbonation test results for mine operations and closure planning}

\subsection{Site specific carbon capture opportunities}

Utilising the mineralisation scenarios identified through carbonation rate calculations and LOM waste rock estimations, the potential offset of $\mathrm{CO}_{2}$ emissions at the Kevitsa site during the operational mining period has been calculated, Table 2. It is noted that these calculations are based on a pure $\mathrm{CO}_{2}$ environment, for material with particle size $<6.3 \mathrm{~mm}$ at $25^{\circ} \mathrm{C}$ and so will overestimate field rates significantly when considering passive schemes, however for active treatment schemes, that enhance the reaction kinetics, the test results may be more closely realised in the field. The estimated yearly $\mathrm{CO}_{2}$ emissions are based on 2016-2018 environmental figures (Boliden Mines 2018). As the finest particle fractions $(<2.3 \mathrm{~mm})$ are known to be the most reactive proportion of waste, scenarios that consider only this size fraction of the waste, based on PSD, have been presented to allow realistic estimates of schemes that do not involve processing of the waste materials to be assessed. 
Table 2 Calculated $\mathrm{CO}_{2}$ offset figures for 2017-2032. EU ETS price based on Markets Insider (2018) figures

\begin{tabular}{|c|c|c|c|c|}
\hline $\begin{array}{l}\text { Mineralisation rate } \\
\text { scenarios }\end{array}$ & $\begin{array}{c}\text { Mineralised } \\
\mathrm{CO}_{2}(\mathrm{Mt})\end{array}$ & $\begin{array}{l}\text { Percentage of total } \\
\mathrm{LOM} \mathrm{CO}_{2} \text { emissions } \\
\text { offset (\%) }\end{array}$ & $\begin{array}{c}\text { Estimated surplus } \\
\mathrm{CO}_{2} \text { emission } \\
\text { offset (tonnes) }\end{array}$ & $\begin{array}{c}\text { Value of } \\
\text { estimated offset } \\
\text { surplus }(€)\end{array}$ \\
\hline WR1 $(0.91 \mathrm{~kg} / \mathrm{t}) \mathrm{WWM}$ & 3.38 & 281 & $2,178,598$ & $43,571,969$ \\
\hline WR1 $(1.30 \mathrm{~kg} / \mathrm{t}) \mathrm{WWM}$ & 4.83 & 402 & $3,626,569$ & $72,531,384$ \\
\hline TA1 $(2.70 \mathrm{~kg} / \mathrm{t})$ WWM & 10.02 & 835 & $8,824,413$ & $176,488,260$ \\
\hline WR2 $(2.75 \mathrm{~kg} / \mathrm{t}) \mathrm{WWM}$ & 10.21 & 850 & $9,010,050$ & $180,201,005$ \\
\hline WR1 $(0.91 \mathrm{~kg} / \mathrm{t})<2.3 \mathrm{~mm}$ & 0.41 & 34 & N/A & N/A \\
\hline WR1 $(1.30 \mathrm{~kg} / \mathrm{t})<2.3 \mathrm{~mm}$ & 0.59 & 49 & N/A & N/A \\
\hline TA1 $(2.70 \mathrm{~kg} / \mathrm{t})<2.3 \mathrm{~mm}$ & 1.23 & 102 & 27,991 & 559,812 \\
\hline WR2 $(2.75 \mathrm{~kg} / \mathrm{t})<2.3 \mathrm{~mm}$ & 1.25 & 104 & 50,731 & $1,014,623$ \\
\hline $\begin{array}{l}\text { Estimated } \mathrm{LOM} \mathrm{CO}_{2} \\
\text { emissions per annum } \\
\text { (tonnes) }\end{array}$ & 75,000 & \multicolumn{2}{|c|}{$\begin{array}{l}\text { EU ETS carbon trading price } \\
\left(€ \text { per } \mathrm{t}\left(\mathrm{CO}_{2}\right)-16 / 10 / 2018\right.\end{array}$} & $€ 20$ \\
\hline
\end{tabular}

LOM - life-of-mine; WR - waste rock; WWM - whole waste mass; TA - tailings ; EU ETS - European Union's Emissions Trading System

The potential financial incentives of implementing an actively engineered system, such as $\mathrm{CO}_{2}$ injection systems or a particle size sorting plant, to achieve theoretical carbonation potential are indicated by the results shown in Table 2 . In the smallest mineralisation estimation, based solely on mineral carbonation of the percentage of $<2.3 \mathrm{~mm}$ waste rock, a $34.49 \%$ offset of estimated LOM emissions was calculated. In a best-case scenario, based solely on estimations in this study, a maximum offset of over $850 \%$ of Kevitsa $\mathrm{CO}_{2}$ emissions has been estimated, with a surplus value of over $€ 180$ million. Future increases in the trading price carbon price may further improve project economics. It has been indicated in a number of industry sources that the price of carbon in trading schemes may increase to as much as $€ 100$ per $t$ if strong action is taken by governments to reduce carbon emissions through the use of pricing schemes. At these prices active carbon capture and storage (CCS) schemes may become increasingly economically viable.

It is further noted that if an engineered scheme was to be implemented post-closure then rates of carbon capture may be significantly increased above those estimated in Table 2 as the duration of the scheme may be extended for many decades before the CCP is exhausted.

The calculations presented in Table 2 are based on the application of rates calculated within carbonation vessel experiments, applied to the known PSD and totals of waste rock present and expected over the LOM at Kevitsa. The monetary calculation of surplus is based on emissions trading system (ETS) carbon trading prices, stated within the table. The scenarios stated within the table are based on application of estimated carbonation rates to either the whole waste mass (WWM) or the finer particle distribution, identified as waste rock with a particle size of $<2.3 \mathrm{~mm}$.

\subsection{Site specific implications for acid mine drainage management}

The results indicate that the carbonation process has the potential to have a positive impact on AMD risk management within waste storage facilities at the site due to the nature of the geochemical impacts associated with the carbonation process. The generation of additional carbonate mineral mass will result in an increase in acid buffering capacity of the waste materials in situ. Given that soluble magnesium carbonates are produced, the potential to raise porewater $\mathrm{pH}$ above $\mathrm{pH} 8$ is increased (at pH levels $>8$ metal mobility is significantly reduced for the majority of metal species associated with sulphide mineralisation). If the carbonation process occurs at a rate under ambient atmospheric $\mathrm{CO}_{2}$ conditions, positive benefits may be realised for materials with low sulphide content under a scenario of passive sequestration where no active 
system is required. The substantiation of these potential passive benefits will require further testing at ambient atmospheric $\mathrm{CO}_{2}$ levels.

Additional opportunities for waste materials with a range of sulphide contents can also be envisaged if an engineered/enhanced carbonation system were to be applied at the site in which $\mathrm{CO}_{2}$ is pumped into the tailings and/or waste rock facility to increase carbonation rates. The likelihood of pumping pure $\mathrm{CO}_{2}$ into such a system may currently be uneconomic but a system that provides direct air capture of carbon dioxide at a concentration of $<100 \%$ would enhance reactions. While the potential to lower porewater $\mathrm{pH}$ is presented by $\mathrm{CO}_{2}$ injection (though carbonic acid production) the results of the carbonation column results demonstrated that $\mathrm{pH}$ was effectively buffered with potential carbonate formations in mineral surfaces buffering above $\mathrm{pH}$ 8. It must be considered that the buffering observed was an outcome of a 1:2 leach test and more testing is required to quantify further conditions within the columns and in situ. Buffering is considered to be caused by chemical weathering of the silicate minerals within the waste rock, consuming $\mathrm{H}^{+}$through incongruent weathering, and alteration of silicates to carbonates (Hitch et al. 2010). The injection of $\mathrm{CO}_{2}$ would have the additional benefit of creating an anoxic environment, which would reduce/prevent sulphide oxidation potential within the waste mass. The production of alkalinity through enhanced precipitation of stable carbonates in the waste rock may therefore have significant positive implications for AMD management at the site.

\subsection{General implications for acid mine drainage management at other sites}

AMD interactions are an important consideration for any CCS scheme, this is particularly so with passive schemes because the processes that drive CCP will also in many cases facilitate AMD neutralisation, given that fluxes of atmospheric water and gas are integral to sulphide oxidation as well as carbonation. As such, assessments of potential AMD impacts are essential to support the potential viability of CCP. Where active schemes are proposed, the injection of $\mathrm{CO}_{2}$ will likely have a net positive effect on AMD risk if carbonic acid production is effectively buffered by carbonation. Where passive schemes are proposed the net effect on AMD risk requires detailed assessment as flux of atmospheric $\mathrm{CO}_{2}$ will for the most part imply flux of oxygen and water (unless oxygen is removed from inflows of gas). An interesting situation may arise whereby primary carbonates are present in material with CCP that is subject to acidity production from sulphide oxidation as the primary carbonates may be dissolved by acidity with $\mathrm{CO}_{2}$ being released, which then in turn may be re-carbonated by weathering of magnesium silicates (the process is in turn is facilitated by the initial acidity release).

The study of carbon fixation along with AMD can be considered an integrated and interrelated assessment as the kinetics of the processes of carbonation and sulphide oxidation will determine porewater buffering and $\mathrm{pH}$, and ultimately metal release, which are key considerations in geochemical modelling and mine closure planning. AMD may be less of a factor in situations where rates of sulphide oxidation are slow relative to rates of carbonation, or in which the sulphide minerals present do not generate acidity/mobile metals during oxidation.

\subsection{Utilisation of carbonation assessment methods for mine closure planning at other sites}

The potential positive impact of mineral carbonation, both passive and enhanced, on both AMD risk and net operation $\mathrm{CO}_{2}$ emissions have been indicated at the study site, given that suitable rock types are found at many other sites across the world it is likely that the findings made herein are applicable to many other locations. This paper has highlighted how carrying out simple, low cost, and short duration geochemical and mineralogical testing can significantly enhance the understanding of mineral carbonation and its impact on mine waste geochemistry. The tests carried out in this study could be applied to many sites worldwide, with minimal financial burden, as part of preliminary assessment of a site's viability for carbon mineralisation schemes as well as giving a greater understanding of the impact of passive carbonation on long-term post-closure geochemical modelling. It should be noted that the methods expressed could be implemented 
at all stages of the mining process from initial core material to closure plans. The utilisation of this kind of assessment allows inclusion of the impact that carbonation may have on long-term mine geochemistry and as such closure plans.

\subsection{Utilisation of carbonation process as part of mine closure planning and repurposing of waste facilities at other sites}

With respect to mine operations and closure, incorporating the concept of the circular economy as part of long-term waste management planning has become an important aspirational target globally in the mining industry, however in practical terms implementing the concept requires identifying the opportunities and meeting numerous technical challenges. Carbon capture offers a significant opportunity in this regard as a positive environmental and economic 'value' can potentially be ascribed to large volumes of 'waste' materials that otherwise are considered a liability from both risk and economic assessment metrics with respect to long-term closure (Sapsford et al. 2016). The repurposing of waste facilities to take advantage of carbon sequestration offers the opportunity to provide economic, environmental and socio-economic benefits.

If an effective CCS project can be implemented after mining operations end, this means that the site is given an effective new 'operational purpose' and may contribute to generating or sustaining employment, supporting local communities, as well as providing the projects main objective of realising the environmental benefits of the significant carbon reduction outcomes.

The potential economic viability of scenarios relating to active CCS schemes will, for the most part, be strongly related to the European Union's Emissions Trading System (EU ETS) trading price of $\mathrm{CO}_{2}$. Future increases in the trading price carbon price may improve project economics further. It has been indicted in several industry sources that the price of carbon in trading schemes may increase as high as $€ 100$ per tonne if strong action is taken by governments to reduce carbon emissions through the use of pricing schemes. At these prices active CCS schemes may become increasingly economically viable, and waste storage facilities that were considered a liability may in the future become a valuable resource.

\section{Acknowledgements}

The authors of this study would like to acknowledge the various individuals at both Cardiff University, Geochemic Ltd and MEM Consultants for their excellent work on this study. We would like to thank Dr Huw Pullin for his contributions in performing XRD analysis. A thank you is given for the contributions of $\mathrm{Dr}$ Ben Gersten and Dr Mark Roberts for their help both constructing and maintaining laboratory experiments over the course of the study. The authors acknowledge financial support from Boliden Mines for an MSc dissertation bursary for Rhys Savage.

\section{References}

Bickle, M, Kampman, N \& Wigley, M 2013, 'Natural analogues', Reviews in Mineralogy and Geochemistry, vol. 77, no. 1, pp. 15-71. Boliden Mines 2018, LOM Schedule Data, Stockholm.

Hitch, M, Ballantyne, S \& Hindle, S 2010, 'Revaluing mine waste rock for carbon capture and storage', International Journal of Mining, Reclamation and Environment, vol. 24, no. 1, pp. 64-79.

Kaszuba, J, Yardley, B \& Andreani, M 2013, 'Experimental perspectives of mineral dissolution and precipitation due to carbon dioxidewater-rock interactions', Reviews in Mineralogy and Geochemistry, vol. 77, no. 1, pp. 153-188.

Kharaka, Y, Cole, D, Thordsen, J, Gans, K \& Thomas, R 2013, 'Geochemical monitoring for potential environmental impacts of geologic sequestration of $\mathrm{CO}_{2}$ ' Reviews in Mineralogy and Geochemistry, vol. 77, no. 1, pp. 399-430.

Königsberger, E, Königsberger, L \& Gamsjäger, $\mathrm{H}$ 1999, 'Low-temperature thermodynamic model for the system $\mathrm{Na}_{2} \mathrm{CO}_{3}-\mathrm{MgCO}_{3}-$ $\mathrm{CaCO}_{3}-\mathrm{H}_{2} \mathrm{O}^{\prime}$, Geochimica et Cosmochimica Acta, vol. 63, no. 19, pp. 3105-3119.

Lackner, K 2003, 'Climate change: a guide to $\mathrm{CO}_{2}$ sequestration', Science, vol. 300, no. 5626, pp. 1677-1678.

Leung, D, Caramanna, G \& Maroto-Valer, M 2014, 'An overview of current status of carbon dioxide capture and storage technologies' Renewable and Sustainable Energy Reviews, vol. 39, pp. 426-443.

Li, J, Hitch, M, Power, I \& Pan, Y 2018, 'Integrated mineral carbonation of ultramafic mine deposits-a review', Minerals, vol. 8, no. 4, p. 147.

Maier, W, Lahtinen, R \& O’Brien, H 2015, Mineral Deposits of Finland, Amsterdam, Elsevier, Netherlands. 
Markets Insider 2018, $\mathrm{CO}_{2}$ European Emission Allowances PRICE Today / $\mathrm{CO}_{2}$ European Emission Allowances Spot Price Chart / Live Price of $\mathrm{CO}_{2}$ European Emission Allowances per Ounce / Markets Insider, viewed 17 October 2018, https://markets.businessinsider.com/commodities/co2-emissionsrechte

Oelkers, E 1999, 'A comparison of forsterite and enstatite dissolution rates and mechanisms', Growth, Dissolution and Pattern Formation in Geosystems, pp. 253-267.

Platen, H \& Wirtz, A 1999, Measurement of the Activity of Soils Using OxiTop Control Measuring System, WTW, viewed 7 September 2018, https://www.wtw.com/en/home.html

Prigiobbe, V, Hänchen, M, Werner, M, Baciocchi, R \& Mazzotti, M 2009, 'Mineral carbonation process for $\mathrm{CO}_{2}$ sequestration', Energy Procedia, vol. 1, no. 1, pp. 4885-4890.

Renforth, P 2019, 'The negative emission potential of alkaline materials', Nature Communications, vol. 10, no. 1.

Sapsford, D, Cleall, P \& Harbottle, M 2016, 'In situ resource recovery from waste repositories: exploring the potential for mobilization and capture of metals from anthropogenic ores', Journal of Sustainable Metallurgy, vol. 3, no. 2, pp. 375-392.

Stockmann, G, Wolff-Boenisch, D, Gíslason, S \& Oelkers, E 2008, 'Dissolution of diopside and basaltic glass: the effect of carbonate coating', Mineralogical Magazine, vol. 72, no. 1, pp. 135-139.

Wilson, S, Dipple, G, Power, I, Thom, J, Anderson, R, Raudsepp, M, Gabites, J \& Southam, G 2009, 'Carbon dioxide fixation within mine wastes of ultramafic-hosted ore deposits: examples from the Clinton Creek and Cassiar Chrysotile deposits, Canada', Economic Geology, vol. 104, no. 1, pp. 95-112. 